\title{
Solubility Study and Purification Of Industrial Triple superphosphate in
} aqueous solution

\author{
E-mail: khouloudnasri06@gmail.com \\ E-mail: hafed.elfeki@yahoo.fr \\ ${ }^{\mathrm{b}}$ Chemical group of Tunisia, Gabes. \\ E-mail: chaker.chtara@gmail.com \\ E-mail: chekir.hassen@gct.com.tn
}

Khouloud Nasri ${ }^{\mathrm{a}}$, Chaker Chtara ${ }^{\mathrm{b}}$, Hassen Chekir ${ }^{\mathrm{b}}$, Hafed Elfeki ${ }^{\mathrm{a} *}$

a Laboratory of Materials Sciences and Environment Science, LR05ES12, University of Sfax, Tunisia.

${ }^{*}$ Corresponding author: E-mail address: hafed.elfeki@yahoo.fr

\begin{abstract}
Triple Superphosphate (TSP) is a chemical fertilizer, acknowledged by its important content of phosphorus, necessary element for plants. It's obtained by adding phosphoric acid to phosphate ore, consisting of calcium phosphate containing many impurities. TSP was dissolved at different temperatures and in various amounts of water, filtered to remove insoluble compounds. Then the ionic conductivity was monitored for each solution as a function of the added amount of TSP. Aqueous solutions were evaporated to dryness and analyzed the $\mathrm{P}_{2} \mathrm{O}_{5}$. The starting materials and final products were analyzed by several methods (XRD, IR, NMR, SEM) confirming that after dissolution the product was purified.
\end{abstract}

\section{Indexing terms/Keywords}

Purification, Triple superphosphate, $\mathrm{P}_{2} \mathrm{O}_{5}$, solvent (water), impurities.

\section{Academic Discipline And Sub-Disciplines}

Environment Science

\section{SUBJECT CLASSIFICATION}

Chemistry Subject Classification

TYPE (METHOD/APPROACH)

Solubility

\section{Council for Innovative Research}

Peer Review Research Publishing System

Journal: Journal of Advances in Chemistry

Vol. 9, No. 2

editorjaconline@gmail.com

www.cirworld.org/journals 


\section{Introduction:}

Triple Superphosphate is acquired by direct acidification natural phosphate by means of phosphoric acid. The corresponding chemical reaction is according in the equation 1 :

$\mathrm{Ca}_{10} \mathrm{~F}_{2}\left(\mathrm{PO}_{4}\right)_{6}+14 \mathrm{H}_{3} \mathrm{PO}_{4}+10 \mathrm{H}_{2} \mathrm{O} \longrightarrow 10 \mathrm{Ca}\left(\mathrm{H}_{2} \mathrm{PO}_{4}\right)_{2}, \mathrm{H}_{2} \mathrm{O}+2 \mathrm{HF}$

Monocalcic monohydrate phosphate $\left(\mathrm{Ca}\left(\mathrm{H}_{2} \mathrm{PO}_{4}\right)_{2}, \mathrm{H}_{2} \mathrm{O}\right)(\mathrm{MCPM})$ is the only form of phosphate of soluble calcium in aqueous middle ${ }^{1}$.This product, appeared in the world in the middle of the forties, was the phosphate manure most used, thanks to its well brought up concentration (46\%) in $\mathrm{P}_{2} \mathrm{O}_{5}$. However, phosphate rock delivers $\mathrm{P}$ at a very slow rate due to its insolubility in water, and modern agricultural practices favor the use of rapidly bio-available $P$ such as that found in mono or diammonium phosphate ${ }^{2-3}$.

The applications of triple superphosphate are restricted in reasons of impurity then a purification is obvious. For its purification we chose technology of recrystallization. To cleanse the TSP by the method of recrystallizing, we have to determine first of all the solubility of this product in the adequate solvent. Because if the phenomenon of recrystallizing starts for sub-saturated or slightly supersaturated solutions, there will be misdeeds on the economic plan and that of the yield efficiency on the process. In this aim, M. Gargouri and H.ELFEKI, in previous reports on purification of an Industrial Fertilizer Diammonium Phosphate (DAP) and Monoammonium Phosphate (MAP) Using Design of Experiments ${ }^{4-5-6}$, used recristallization as method of purification. In another way, it is necessary to clean phosphoric acid and natural phosphate, with which its Purification as such is impossible. The Purification of phosphoric acid is made in general by extraction LiqLiq. In fact, this extraction process cannot be regarded as an industrially advantageous process due to its complicated steps ${ }^{7}$.

In the present work, we are interested in eliminating impurities from industrial TSP. This compound contains insoluble impurities in the water, yet the cleansed industrial Triple superphosphate is soluble in $93 \%$ near in the water. This incites us to study the solubility while using the technique of conductivity. On the other hand, the physicochemical characterization of triple superphosphate upstream and downstream of the purification process is aimed at determining the performance of recrystallization.

\section{Experimental}

The starting product used was Tunisian TSP (triple super phosphate) obtained industrially by reacting ore from the Gafsa deposits with raw $33 \% \mathrm{H}_{3} \mathrm{PO}_{4}$. The dry product was a free flowing powder. The IR spectra were determined by a FTIR system spectrumBX Perkin-Elmer spectrometer. Impurities were analyzed by ICP spectroscopy. The analysis by scanning electron microscope (SEM) is determined with a MEB Philips serie XL 30. The spectra of X-ray powder diffraction (XRPD) is determined by a Seifert 3000 . T.T. spectrometer. ${ }^{31} \mathrm{P}$ NMR were obtained with a Bruker 300 spectrometer. Conductivity measurements were performed using a Metrhom Herisau 712 conductometer. $\mathrm{P}_{2} \mathrm{O}_{5}$ was analysed by a gravimetric method envolving molybdate precipitation. This method is described in more detail in the standards used in industry ${ }^{8}$. Melting points were determined with a by means of a device of the type " Banc Kofler ". Recristallization experiments of TSP were carried between $273-400 \mathrm{~K}$ and with regular agitation. The suspension was dissolved in $100 \mathrm{ml}$ of solvent (water), filtered and cooled to $273 \mathrm{~K}$ whereupon crystals appeared.

\section{Results and discussion}

\subsection{Solubility}

In the present work, as illustrated respectively in Fig. 1,2,3 and 4, we measured the various values of the conductivity according to the concentration of the TSP with various temperatures $\left(8,25,40\right.$ and $\left.60^{\circ} \mathrm{C}\right)$. The dissolution of phosphogypsum followed by similar conductivity measurements was presented previously ${ }^{9}$. We notice that curves above present a common characteristic it is the change of slope in a certain concentration of the TSP. The method schedules allowed us to determine the intersection points of the tangents (PIDT) which are observed towards 135,120, 115 and 80 $\mathrm{g} / \mathrm{L}$, respectively for the temperatures $8,25,40$ and $60^{\circ} \mathrm{C}$. Then we asked the question on the relation which exists between these points (PIDT) and the solubility. As first idea we can attribute these concentrations to values of solubility, seen that these values decrease according to the increase of the temperature. This is in good agreement with the fact that the dissolution of the TSP in the water turns out experimentally an exothermic phenomenon and according to the law of moderation any increase of the temperature favors the endothermic direction. 


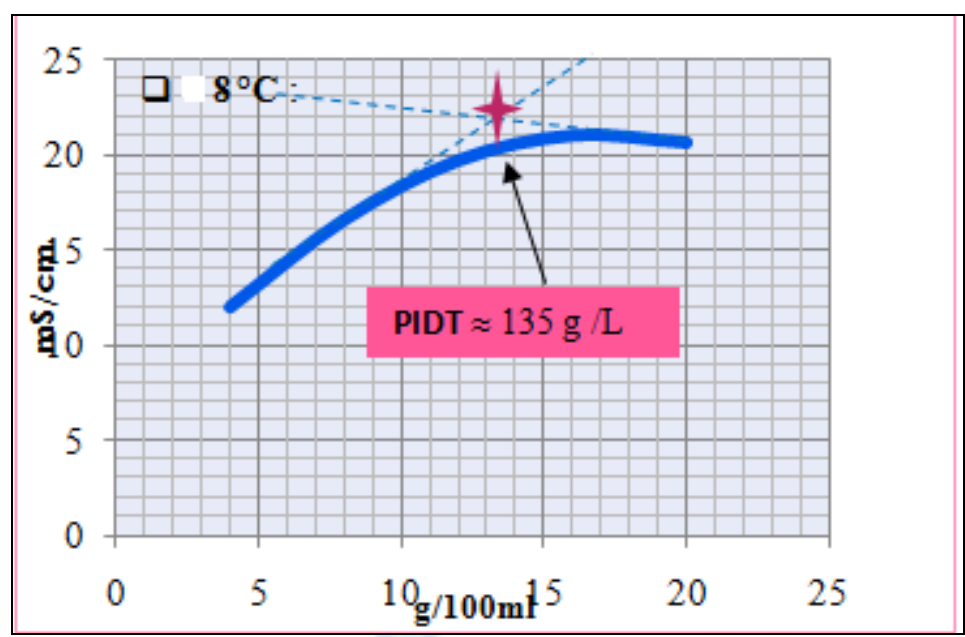

Fig 1 : The curve of conductivity according to the concentration of the TSP in $8^{\circ} \mathrm{C}$ (intersection point of tangents: PIDT)

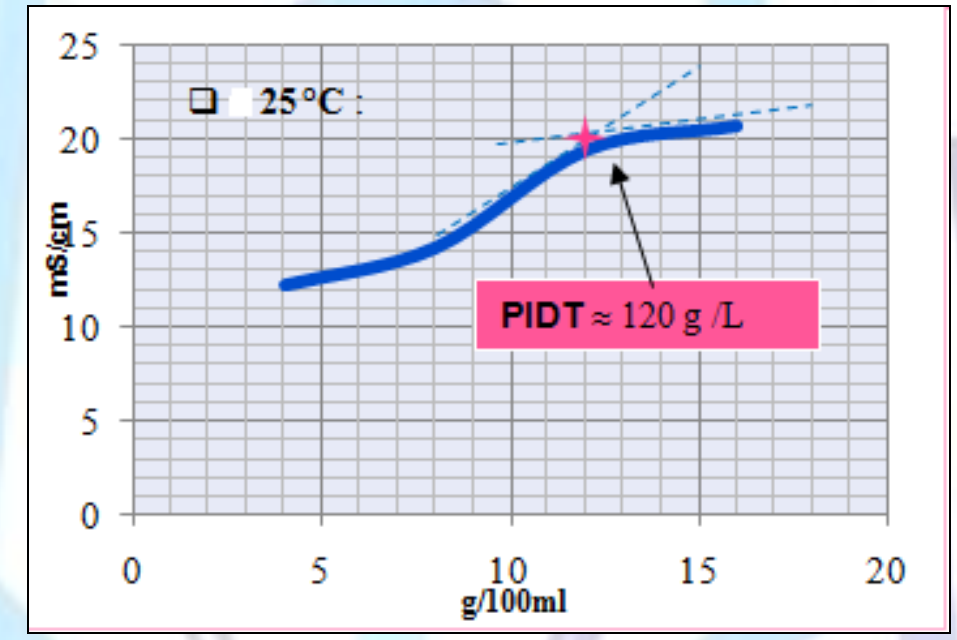

Fig 2 : The curve of conductivity according to the concentration of the TSP in $25^{\circ} \mathrm{C}$

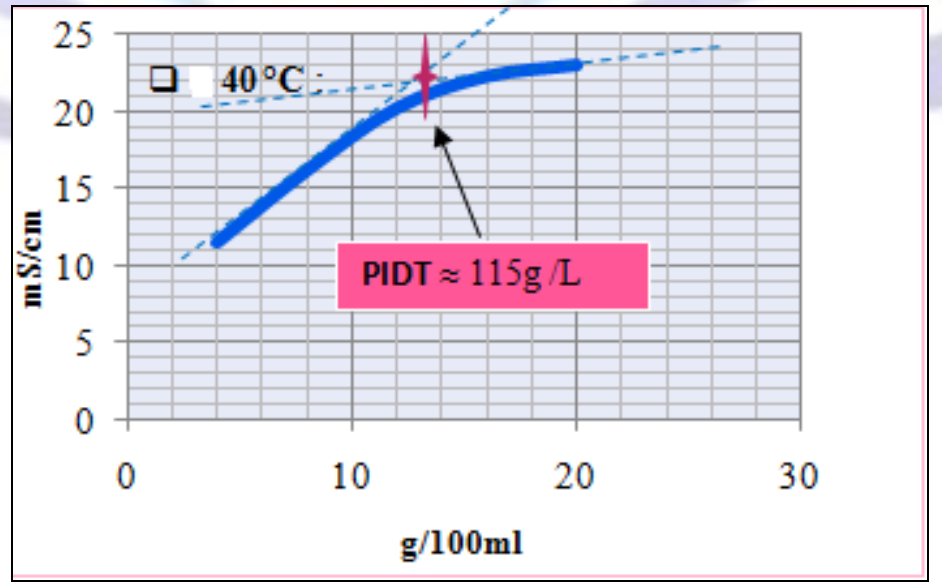

Fig 3 :The curve of conductivity according to the concentration of the TSP in $40^{\circ} \mathrm{C}$ 


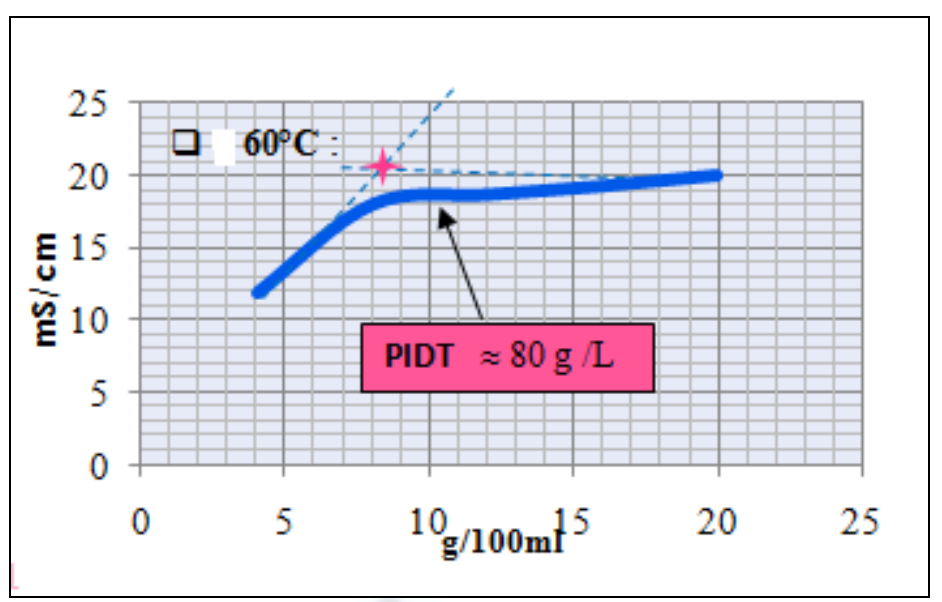

Fig 4: The curve of conductivity according to the concentration of the TSP in $60^{\circ} \mathrm{C}$

\subsection{Recrystallization:}

We realized at this stage the dosage of three types of $\mathrm{P}_{2} \mathrm{O}_{5}$ which are the total $\left(\% \mathrm{P}_{2} \mathrm{O}_{5}(\mathrm{~T})\right)$, the water soluble $\left(\% \mathrm{P}_{2} \mathrm{O}_{5}(\right.$ ws) $)$ and soluble water-citrate $\left(\% \mathrm{P}_{2} \mathrm{O}_{5}(\mathrm{~S}(\mathrm{~W}+\mathrm{C}))\right.$. The dosage was made as well for the cleansed and not cleansed sample while using the gravimetric method. We collected the results of the percentages in $\mathrm{P}_{2} \mathrm{O}_{5}$ of industrial TSP treated in upstream and downstream of the purification in the figure 5 .

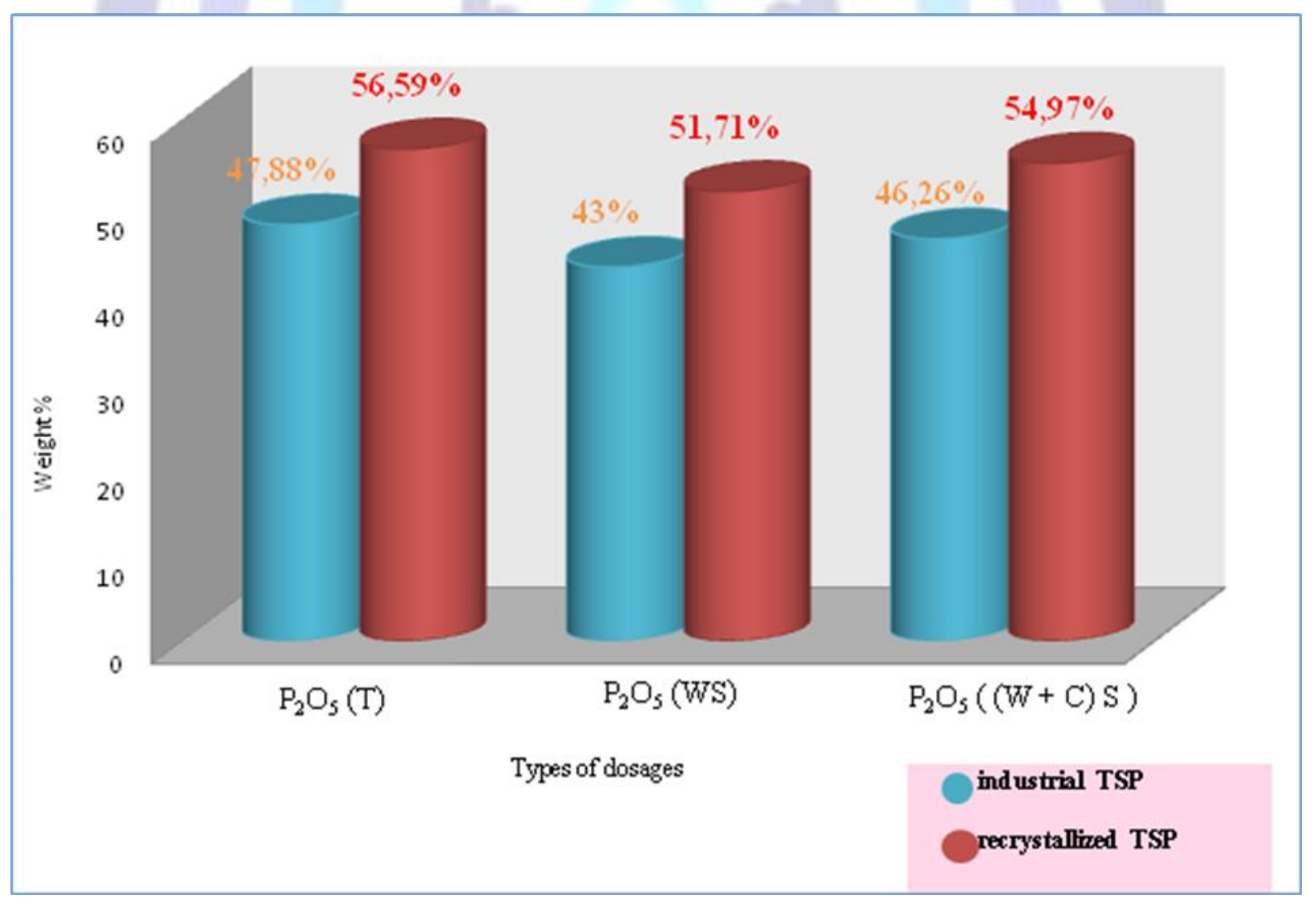

Fig 5: Diagram of percentages in $\mathrm{P}_{2} \mathrm{O}_{5}$ of industrial TSP treated in upstream and downstream of the purification

We notice, in the diagram above that the percentages in $\mathrm{P}_{2} \mathrm{O}_{5}$ of the cleansed treated industrial TSP were increased with regard to those of the same TSP before recrystallizing for example the $\left(\% \mathrm{P}_{2} \mathrm{O}_{5}(\mathrm{~T})\right)$ of the raw TSP is equal to $47.88 \%$ and increases to $56.59 \%$ after purification. These results are consequently, in good agreement with the decrease of the impurities described by the technique of analysis ICP.

The obtained results (mass percentage, ppm) are converted with regard to the same mass percentage in $\mathrm{P}_{2} \mathrm{O}_{5}$. The table 1 summarizes the obtained results and the calculations of the rates of purification for every impurity. We notice that the 
quantity of the totality of the impurities fell with rates varying of $99 \%$ in the case of the aluminum until the $52 \%$ for the manganese. It this is understandable by the fact that the impurities existing initially in the not cleansed TSP do not have the same complexing constants with their online entourages. Their eliminations afterward (through the recrystallizing) is not made quantitatively in the same way, while treating in the same conditions thermodynamics. To see better the decrease of the impurities after the recrystallizing, we realized a diagram illustrated by the figure 6 .

Table 1: Contents of the impurities (to the same $\mathrm{P}_{2} \mathrm{O}_{5}$ ) present in the TSP in upstream and downstream of the recrystallizing.

\begin{tabular}{|c|c|c|c|c|c|c|c|c|}
\hline Impureties & $\begin{array}{c}\mathrm{Fe} \\
(\mathrm{ppm})\end{array}$ & $\begin{array}{c}\text { Al } \\
(\mathrm{ppm})\end{array}$ & $\begin{array}{c}\text { Mg } \\
(\mathrm{ppm})\end{array}$ & $\begin{array}{c}\mathrm{Cr} \\
(\mathrm{ppm})\end{array}$ & $\begin{array}{c}\mathrm{Zn} \\
(\mathrm{ppm})\end{array}$ & $\begin{array}{c}\text { Cd } \\
(\mathrm{ppm})\end{array}$ & $\begin{array}{c}\text { Mn } \\
(\mathrm{ppm})\end{array}$ & $\begin{array}{c}\mathrm{V} \\
(\mathrm{ppm})\end{array}$ \\
\hline Industrial TSP & 3692 & 4821 & 9426 & 269 & 317 & 39 & 46 & 81 \\
\hline recrystallized TSP & 335 & 46 & 2644 & 50 & 131 & 7 & 22 & 12 \\
\hline Rate of purification & $91 \%$ & $99 \%$ & $72 \%$ & $81 \%$ & $59 \%$ & $82 \%$ & $52 \%$ & $85 \%$ \\
\hline
\end{tabular}

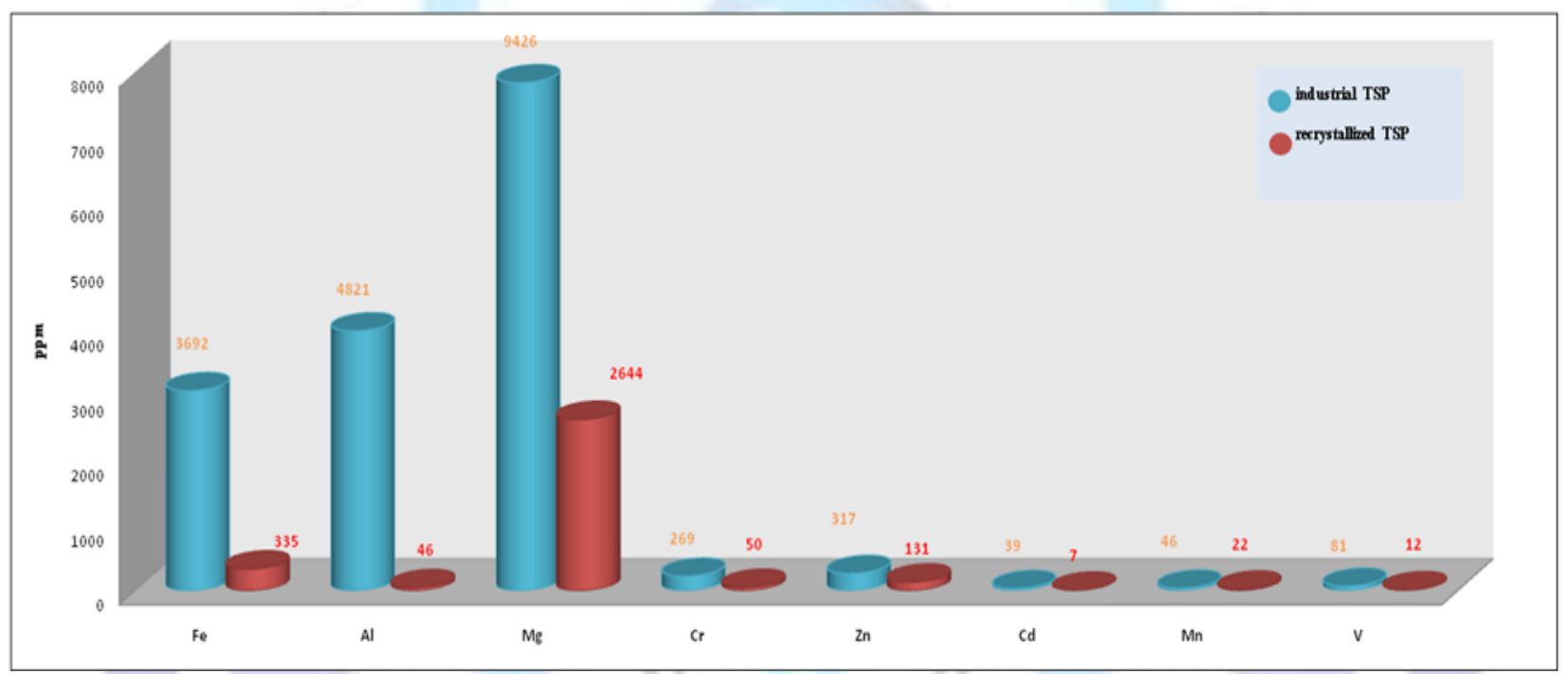

Fig 6: Diagram of contents of the impurities (to the same $\mathrm{P}_{2} \mathrm{O}_{5}$ ) present in the TSP in upstream and downstream of the recrystallizing.

The diagram above presents us an important decrease at the level of the contents of the impurities in our product after the purification. Let us note, that there is a relatively important decrease for certain elements, among them we can quote for example, Fe and the Al. Indeed their contents fell respectively of $3692 \mathrm{ppm}$ until $335 \mathrm{ppm}$ and of 4821 ppm until 46 ppm.

We determined the melting point of the industrial TSP treated before and after purification by means of a device of the type " Banc Kofler ". The obtained results are illustrated in the table 2.

Table 2: Melting point of industrial TSP treated in upstream and downstream of the purification

\begin{tabular}{|c|c|}
\hline Sample & Melting Point \\
\hline Industrial TSP & $117^{\circ} \mathrm{C}$ \\
\hline Recrystallized TSP & $214^{\circ} \mathrm{C}$ \\
\hline
\end{tabular}

The melting point of the treated industrial TSP is equal in $117^{\circ} \mathrm{C}$, while the melting point of the sample after purification is equal in $214^{\circ} \mathrm{C}$. This increase is observed further to the elimination of the existing impurities initially in the not cleansed industrial TSP. It this is understandable by the fact that the average value relative to the melting points of the impurities is lower than the pure extra value of the melting point of the TSP. 
The IR spectra illustrating the main phosphate vibrations near $1000 \mathrm{~cm}^{-1}$ are shown in Fig.7 and Fig.8. The spectra also show water molecule scissoring modes at $1600 \mathrm{~cm}^{-1}$, and $\mathrm{OH}$ stretching vibrations from $3300 \mathrm{~cm}^{-1}$ to $3700 \mathrm{~cm}^{-1}$. Fully deprotonated orthophosphate IR absorption occurs at $1005 \mathrm{~cm}^{-1}$, but when partially protonated, acid phosphate groups present separate PO vibrations and multiple peaks. The spectra obtained for raw or recrystallized TSP show 5 main peaks at $665 \mathrm{~cm}^{-1}, 847 \mathrm{~cm}^{-1}, 946 \mathrm{~cm}^{-1}, 1072 \mathrm{~cm}^{-1}$ and $1215 \mathrm{~cm}^{-1}$. These results are similar to those reported by Tarang et al and E.Fernández et al ${ }^{10-11-12}$, in a previous report on calcium phosphate cements, or by Boonchom ${ }^{13}$, in a study of the rapid precipitation of MCPM in aqueous acetone media. The spectra agree with the one obtained for the synthetic MCPM. The water absorption bands are located at $1650 \mathrm{~cm}^{-1}$ and $3458 \mathrm{~cm}^{-1}$ for free water and $2900 \mathrm{~cm}^{-1}$ for bound water, in agreement with Boonchom ${ }^{13}$.

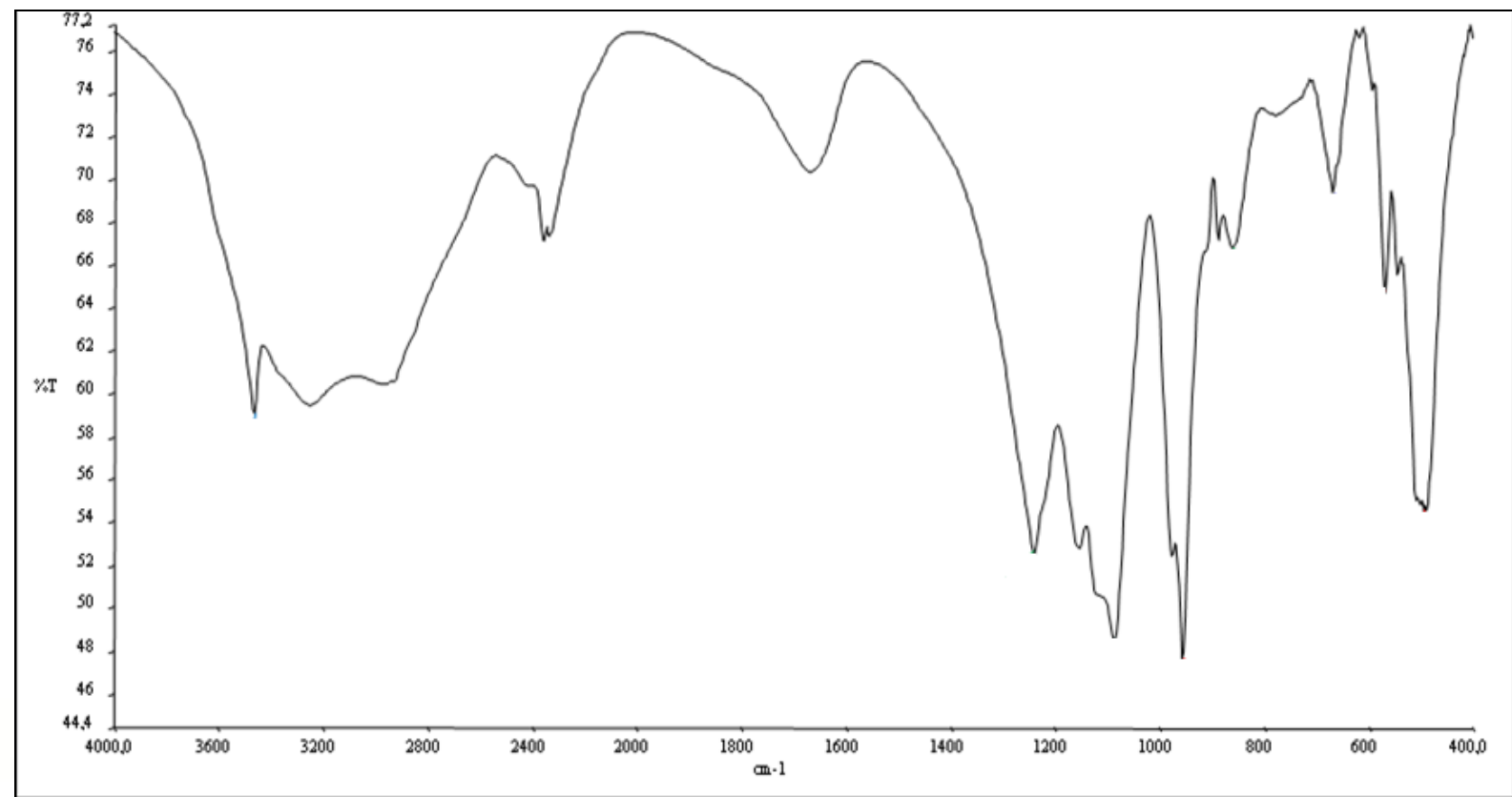

Fig.7: Absorption spectrum IR of industrial TSP

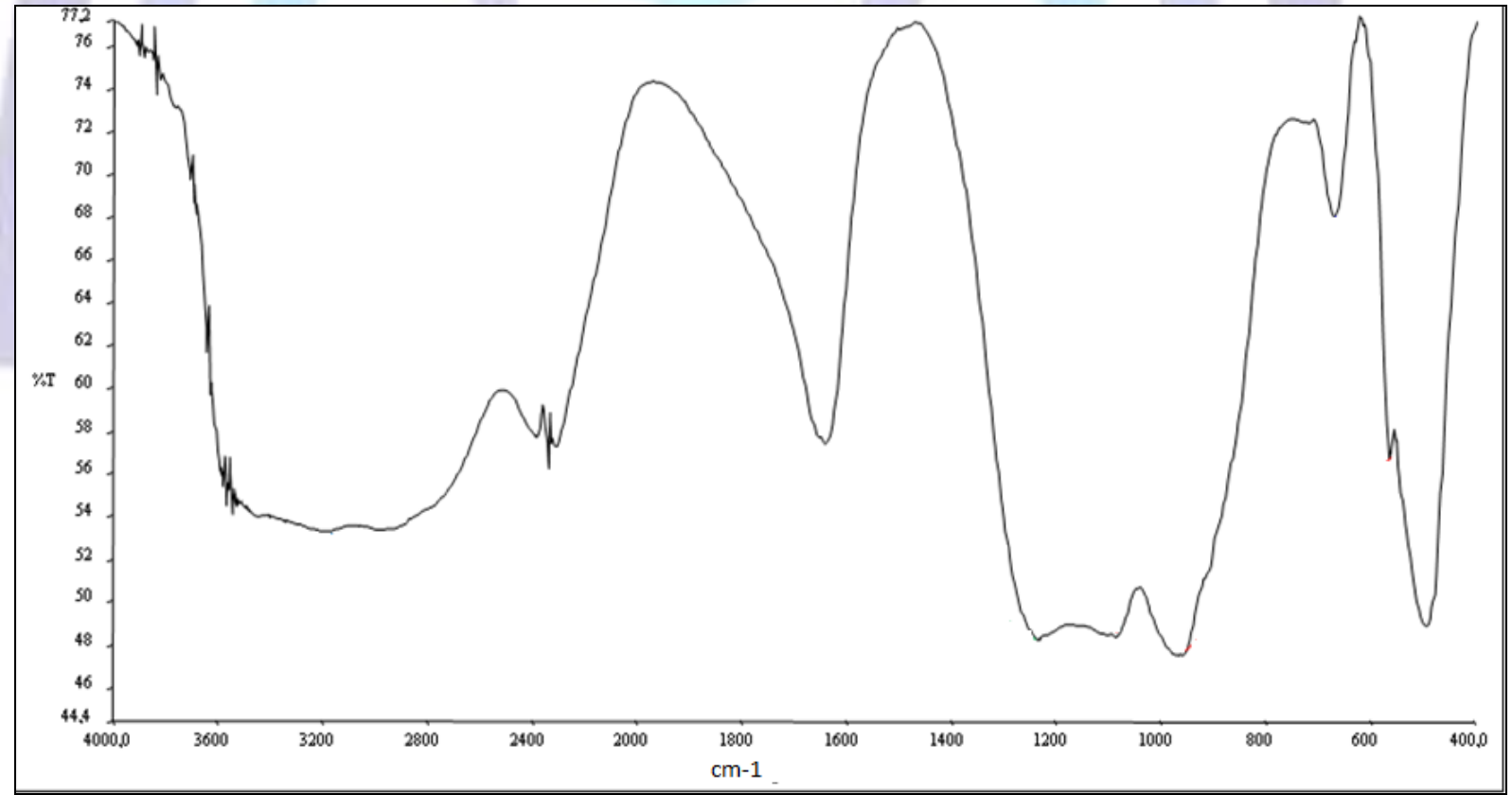

Fig.8: Absorption spectrum IR of recrystallized TSP

In addition, the analysis by electron microscope with sweeping (MEB) of the TSP in upstream and downstream purification showed that the lines relative to the impurities Aluminum, Fluoride and Iron are absent after the purification of the TSP (figure 9). 


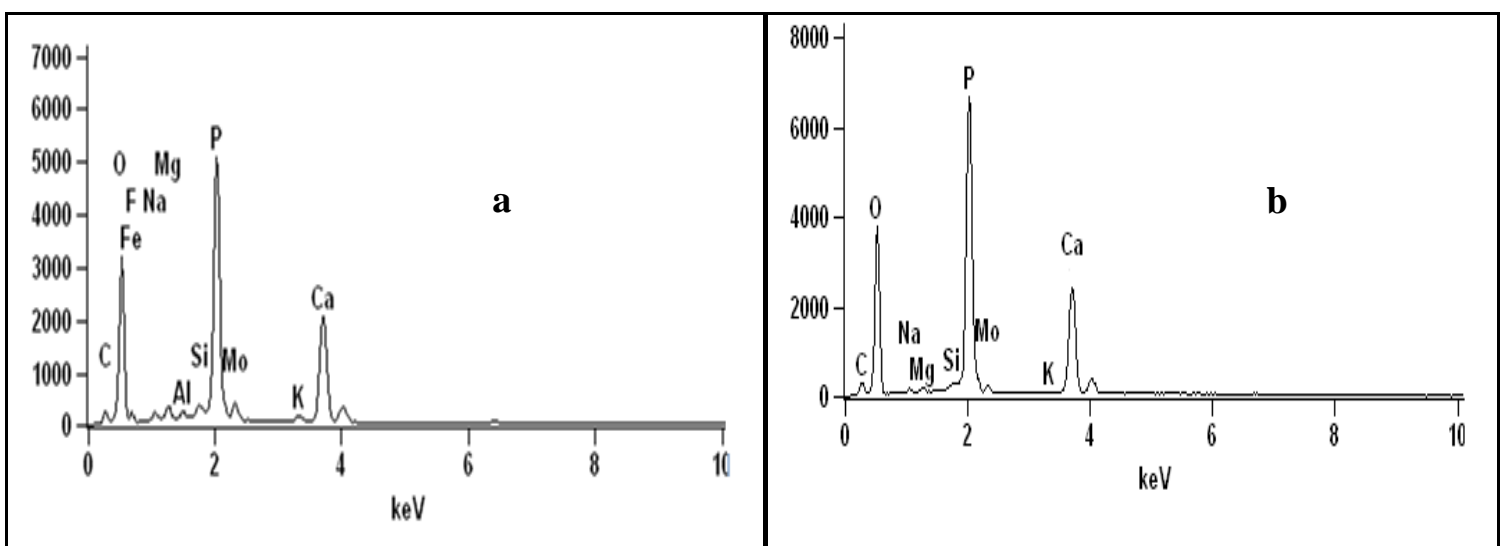

Fig 9: The analysis by MEB of the industrial TSP upstream (a) and downstream (b) from the recrystallization

We also made the micrograph forms with various enlargements. They are presented on figures 10 and 11.
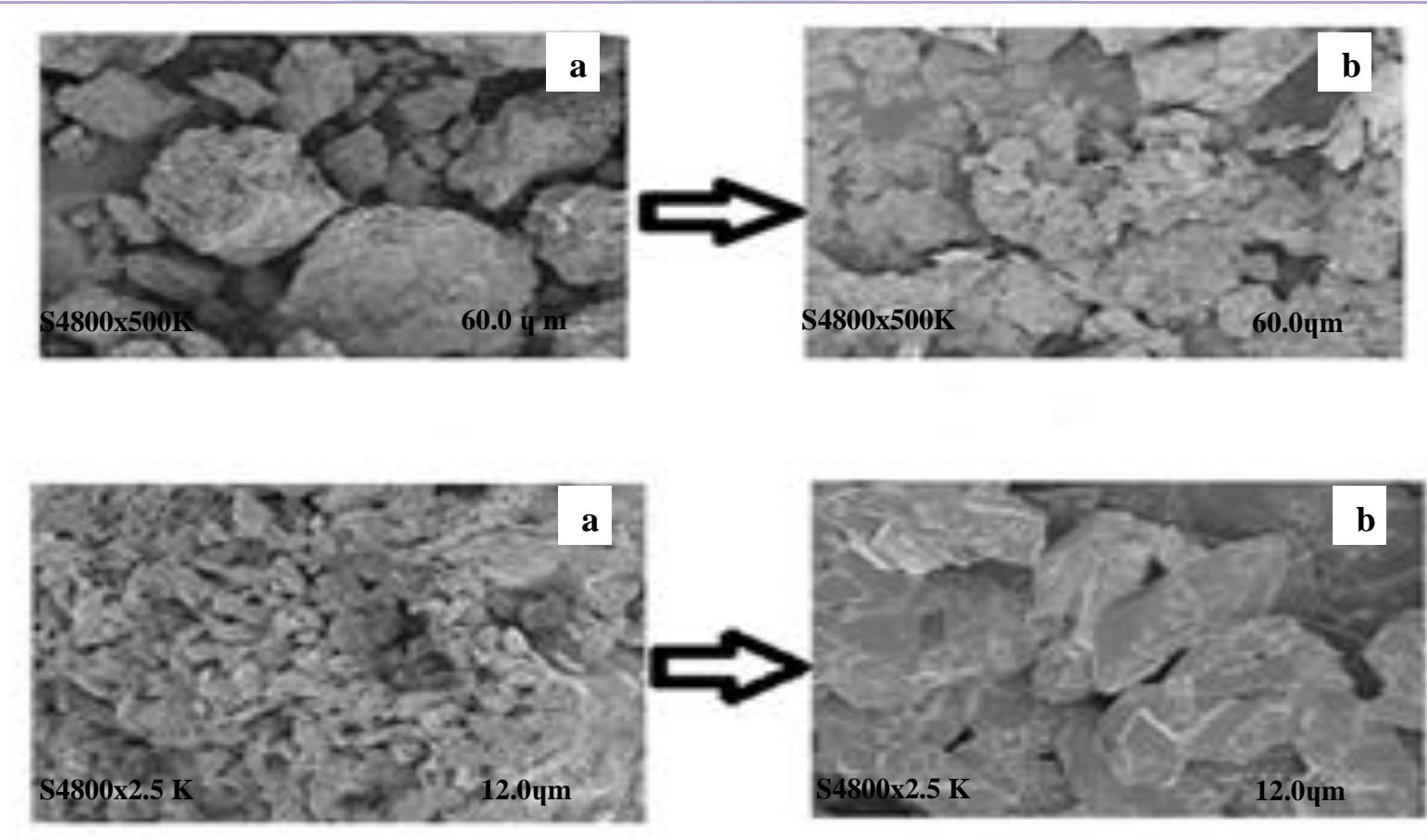

Fig 10: Micrograph by MEB of the industrial TSP upstream (a) and downstream (b) from the recrystallization

The figure 10 shows us a change at the level of type of the grains of the TSP after the purification, even in low enlargement. These grains appear in the form of needles. This lets us think that the triple superphosphate lost certain impurities after the purification. To see well the change of aspect of our cleansed product we made another micrograph form for a higher enlargement. Similar images were found by Boonchom ${ }^{13}$ and Tarang et $\mathrm{al}^{10}$. 


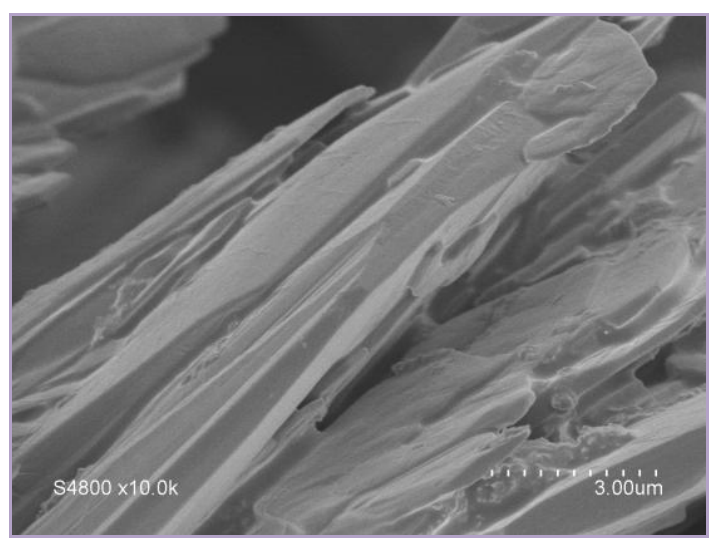

Fig 11: Micrograph by MEB of the grains of the recrystallized TSP In a very high enlargement

This last micrograph form proves that our product has sudden an elimination of the impurities because the structure in needle shows itself clearly.

XRD patterns are shown in Fig.12 to illustrate the presence of main cristalline phases. The analysis by X-ray diffraction showed that the purification of the TSP did not change the crystalline system (monoclinic). Knowing that the monocalcium phosphate monohydrate crystallize in triclinic system and correspond to the JCPDS reference (00-003-0284) so our product cristallize in monoclinic system. This is due to the presence yet of impurities. These conform well to the chemical analytic results which mentioned previously.
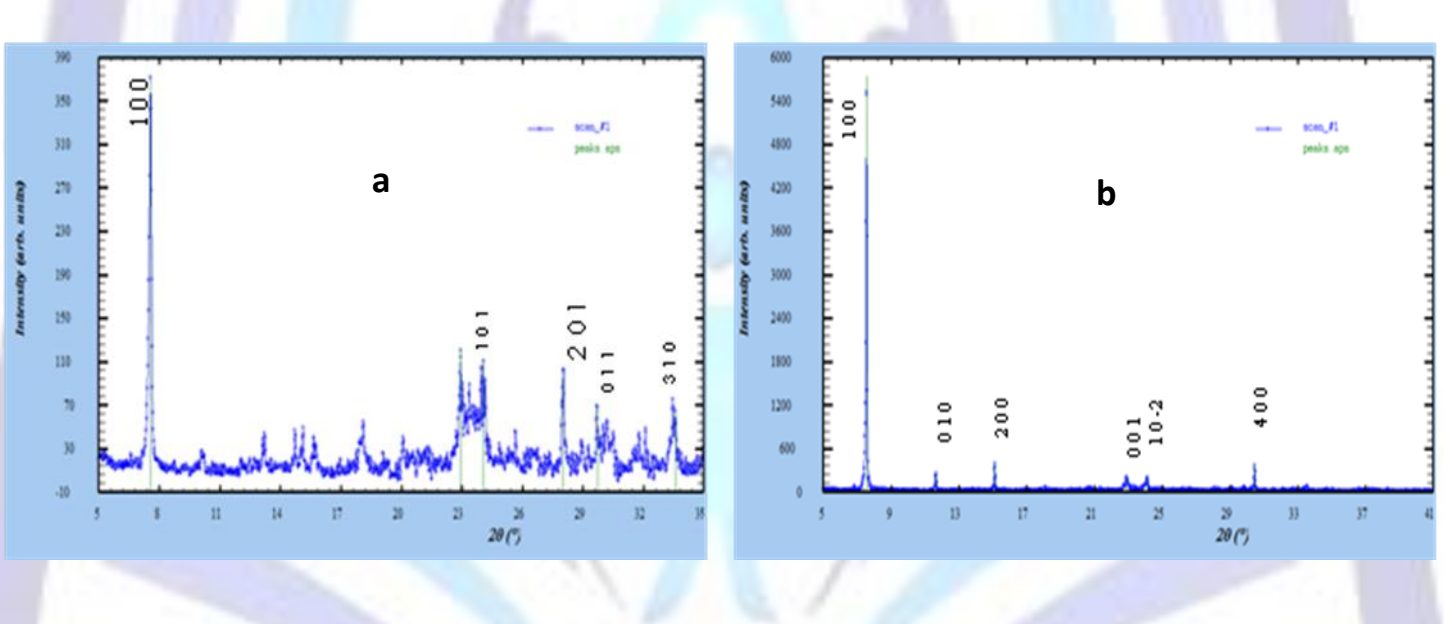

Fig 12: The analysis by X-ray diffraction of the industrial TSP upstream (a) and downstream (b) from the recrystallization

In the purpose, to see better the influence of the adopted process of purification, on the results of diffraction of the X-rays, we determined the crystallographic parameters of the stitch of the industrial TSP treated before and after the purification by using the DICVOL program, the obtained results are illustrated in the table 3. 
Table 3: Crystallographic parameters of industrial TSP treated in upstream and downstream of the purification

\begin{tabular}{|c|c|c|c|c|c|c|}
\hline Samples & $\begin{array}{c}\text { Crystal } \\
\text { System }\end{array}$ & $\begin{array}{c}\text { Espace } \\
\text { Group }\end{array}$ & $\begin{array}{c}\mathbf{a}\left(\mathbf{A}^{\circ}\right) \\
\mathbf{\pm 0 . 0 0 9}\end{array}$ & $\begin{array}{c}\mathbf{b}\left(\mathbf{A}^{\circ}\right) \\
\mathbf{\pm 0 . 0 0 9}\end{array}$ & $\begin{array}{c}\mathbf{c}\left(\mathbf{A}^{\circ}\right) \\
\mathbf{\pm 0 . 0 0 9}\end{array}$ & $\boldsymbol{\beta}\left(^{\circ}\right)$ \\
\hline $\begin{array}{c}\text { Industrial TSP } \\
\text { Mecrystallized } \\
\text { TSP }\end{array}$ & Monoclinic & $\mathrm{P} 2 / \mathrm{m}$ & 11,657 & 3,339 & 8,008 & 94,448 \\
\hline & & $\mathrm{P} 2 / \mathrm{m}$ & 11,749 & 3,886 & 7,618 & 90,305 \\
\hline
\end{tabular}

These values show that there is a preservation of crystalline structure between the not cleansed industrial TSP and that cleansed. But there is a change at the level of the crystallographic parameters $((a, b, c$ and $\beta)$, which shows well the elimination of certain impurities after recrystallizing.

The analysis by solid state nuclear magnetic resonance of the industrial TSP upstream and downstream from the recrystallization showed that in the spectra NMR of the ${ }^{31} \mathrm{P}$ of the cleansed industrial TSP, a disappearance of the widest peak with regard to that not cleansed (figure 13). Besides, a light gap of chemical movement of two other peaks can be highlighted. In that case, the grouping phosphates present two different environments. The disappearance of the widest peak shows good, once again, the disappearance of the impurities which surround the phosphate. In this aim, Pourpoint et $\mathrm{al}^{14}$ report the experimental ${ }^{31} \mathrm{P}$ NMR spectrum to show two peaks for MCPM related to the two different P environments with signals at $-4.2 \mathrm{ppm}$ and $0.3 \mathrm{ppm}$.
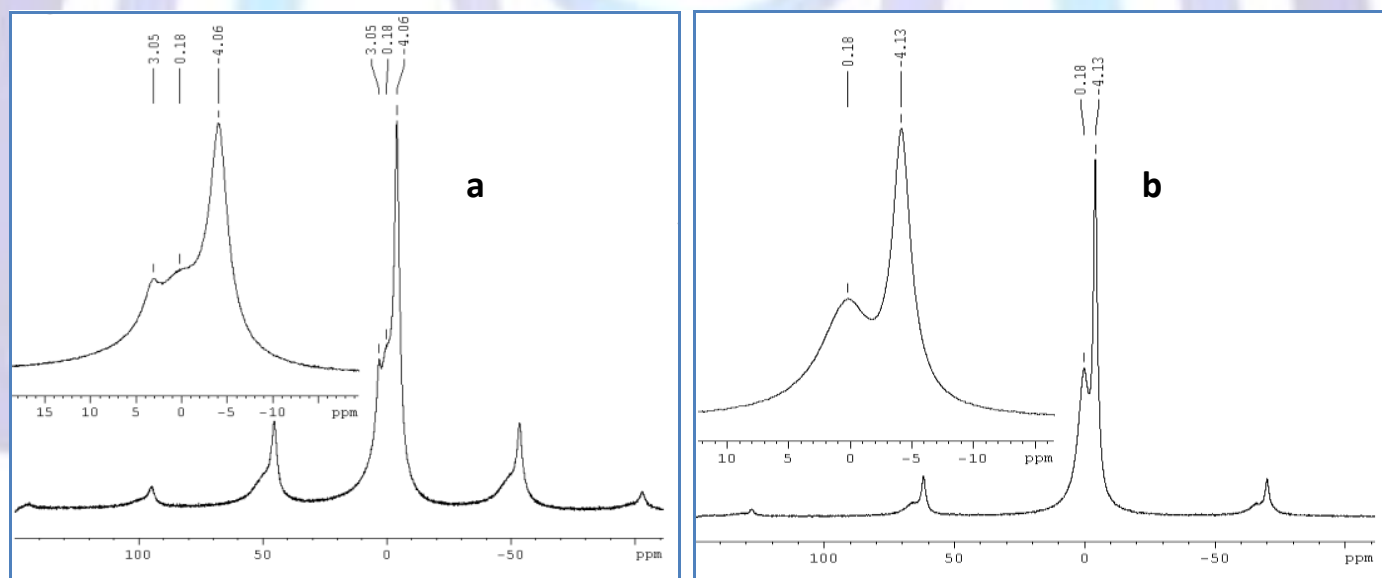

Fig 13: The analysis by ${ }^{31}$ P NMR of the industrial TSP upstream (a) and downstream (b) from the recrystallization.

\section{Conclusion}

Raw TSP manufactured by reaction of phosphoric acid with phosphate ore has a relatively high $\mathrm{P}_{2} \mathrm{O}_{5}$ content of $46 \%$. The recrystallisation of this product in water dissolves monocalcium phosphate monohydrate, with a higher $\mathrm{P}_{2} \mathrm{O}_{5}$ content of $56.59 \%$. This represents the highest amount of soluble phosphate possible to make in solid form with calcium. The analysis by ICP and scanning electron microscope (SEM) shows that the major impurities are eliminated after recrystallization especially. Use of this recrystallized compound as fertilizer will bring the largest amount of available $P$ with the lowest quantity of insoluble impurities. However, it is known that a fraction of soluble $P$ reacts in soils to form insoluble compounds, for instance calcium, iron or aluminum phosphates, by reacting with the mineral elements in soils. Despite such transformations ${ }^{15}$, the phosphates may still be mobilized later on by plants during diagenesis and production of organic acids by phytometabolism. 


\section{REFERENCES}

1. Nessiri, M., AMMAR N. 2009.,Optimisation du procédé SIAPE de Fabrication du triple superphosphate (TSP). Groupe Chimique Tunisien (GCT), Janvier 2009.

2. Ross, W.H., Merz, A.R., Jacob, K.D. 1929.Preparation and properties of the ammonium phosphates. Ind.Eng.Chem. 21, 286-289.

3. Duraisamy,V.P. Role of Inorganic and Organic soil Admendments. 2005. Austalian Journal of Soil Research.

4. Gargouri, M., El Feki, H., Chtara, C., Sharrock, P., Nzihou, A.2010. Synthesis and Physicochemical Characterization of Pure Monoammonium Phosphate (MAP) from Industrial Fertilizer. Journal of Chemistry and Chemical Engineering, June 2010, Volume 4, No.6 (Serial No.31) USA, ISSN 1934-7375, 49-57.

5. Gargouri, M., El Feki, H., Chtara, C., Sharrock, P., Nzihou A., 2011. Synthesis and Physicochemical Characterization of Pure Diammonium Phosphate from Industrial Fertilizer. Ind. Eng. Chem. Res., 50, 6580-6584.

6. Gargouri, M., El Feki,.Chtara H.,C, Sharrock P., Nzihou A. 2012. Experimental Study of the Purification of an Industrial Fertilizer (Mono-Ammonium Phosphate) to Larger Scale Using an Experimental Design. International Journal of Materials Engineering. 2(4): 32-37.

7. Akiyama A., 1976. studies on Chemical Fertilizers, K.K.Nissin Syuppan,

8. ISO 6598:1985, Fertilizers - Determination of phosphorus content - Quinoline phosphomolybdate gravimetric method.

9. Hammas, I.,; Horchani-Naifer K., Mokhtar F. 2013. Solubility study and valorization of phosphogypsum salt solution. International journal of mineral processing 123, 87-93.

10. Tarang, R., Desai, S., Bhaduri B., Cuneyt Tas, A. A., 2007. self-setting monetite $\left(\mathrm{CaHPO}_{4}\right)$ cement for skeletal repair, Advances in bioceramics and biocomposites II, The American Ceramics Society, 61-69.

11. Fernández, E., Gil, F..J., Ginebra, M.P., Driessens, F.C.M., Planell, J. A., Best, S.M.,1999. Calcium Phosphate Bone Cements for Clinical Applications, Part I, Solution Chemistry J Mater Sci:Mater Med. 10, 169-176.

12. Fernández, E., Gil, F.J., Ginebra, M.P., Driessens, F.C.M., Planell, J. A.,; Best, S.M., 1999. Calcium Phosphate Bone Cements for Clinical Applications, Part II, Precipitate Formation during Setting Reactions, J Mater Sci:Mater Med., 10, 177-184.

13. Boonchom B., 2009. Parallegrram-like microparticles of calcium dihydrogen phosphate monohydrate $\left(\mathrm{Ca}\left(\mathrm{H}_{2} \mathrm{PO}\right)_{2}\right.$, $\mathrm{H}_{2} \mathrm{O}$ ) obtained by a rapid precipitation route in aqueous and acetone media, Journal of Alloys and compounds 482, 199-202.

14. Pourpoint, F., Gervais, C., Bonhomme-Coury, L., Aaïs, T., Coelho, C., Mauri, F., Alonso, B., Babonneau, F., Bonhomme, C. 2007. Calcium Phosphtes and Hydroxyapatite : Solid-State NMR Experiments and First-Principles Calculations, Appl.Magn.Reson, 32, 435-457.

15. McBeath, T. M., Lombi, E., McLaughlin, M. J., Bünemann, E. K. 2009.. Exchangeability of orthophosphate and pyrophosphate in soil: a double isotopic labeling study, Plant Soil, 314, 243-252.

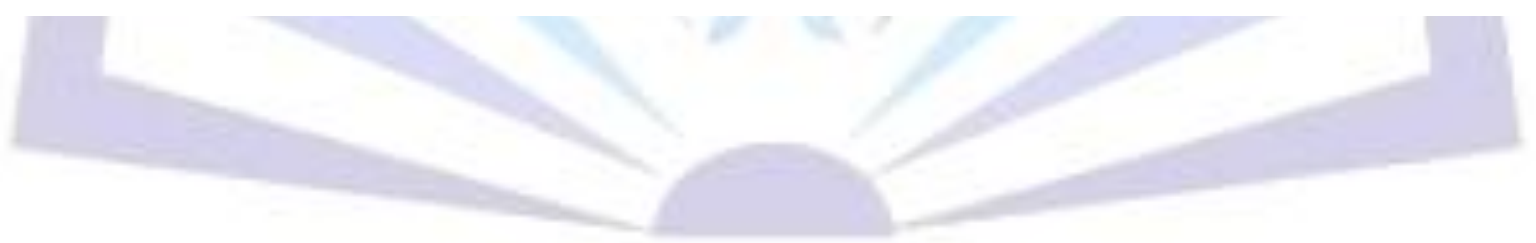

